\title{
EI discurso gráfico en cubiertas de libros. \\ Un laboratorio de investigación para crear metáforas visuales \\ The graphic discourse on book covers. \\ $A$ research laboratory to create visual metaphors
}

DOI: $10.46932 / \mathrm{sfjdv} 1 \mathrm{n} 4-007$

Received in: August 1st, 2020

Accepted in: September 30th, 2020

\author{
Leire Fernández Iñurritegui \\ Doctora en Bellas Artes por la UPV/EHU \\ Profesora Titular de Diseño Gráfico \\ Facultad de Bellas Artes \\ Universidad del País Vasco/Euskal Herriko Unibertsitatea (UPV/EHU) \\ Bilbao, España \\ E-mail: leire.fernandez@ehu.eus \\ Eduardo Herrera Fernández \\ Doctor en Bellas Artes por la UPV/EHU \\ Profesor Titular de Diseño Gráfico \\ Facultad de Bellas Artes \\ Universidad del País Vasco/Euskal Herriko Unibertsitatea (UPV/EHU) \\ Bilbao, España \\ E-mail: eduardo.herrera@ehu.eus
}

\begin{abstract}
RESUMEN
Desde la necesidad de estimular mecanismos de investigación aplicada, concebidos para plantear nuevos fundamentos metodológicos en los procesos de enseñanza-aprendizaje en el campo del diseño gráfico, presentamos algunas reflexiones previas en torno a una propuesta docente que actualmente estamos desarrollando en el primer acercamiento del alumnado a la disciplina del diseño gráfico. Una experiencia práctica apoyada en el diseño de cubiertas de libros y basada en la experimentación sobre la potencial dimensión metafórica de una selección de objetos cotidianos, con el objetivo de adquirir diferentes saberes referidos a la percepción y análisis del contexto socio-cultural y con ello poder acceder a diversos conocimientos sobre las relaciones visuales que ayudan a sentir y a pensar al ser humano. En definitiva, un procedimiento de creación que plantea convertir el aula en un laboratorio de investigación creativa que procure generar experiencias visuales para ver «más allá». Algo que, en definitiva, determina el concepto general del diseño gráfico.
\end{abstract}

Palabras clave: Diseño gráfico, Investigación, Enseñanza, Metáfora, Discurso.

\begin{abstract}
From the need of stimulating applied research mechanisms, which are conceived in order to set out new methodological basics in teaching-learning processes in the field of graphic design, this paper aims to show some first reflections on the teaching proposal that we already are carrying out as a way to approach graphic design to students that are just starting in the field. We purpose a practical experience relying on book covers design and based on experimentation with the potential metaphoric dimension of a selected group of everyday objects. This practical experience has the aim to achieve different kind of knowledge related to perception and analysis of the socio-cultural context that surround us in order to
\end{abstract}


access the diverse kind of knowledge about the visual relations that help human beings in feeling and thinking. In a nutshell, a procedure of creation that sets out to transform the lecture room in a laboratory of creative research that tries to generate visual experiences to «look further». Something that, in short, determines the main idea of graphic design.

Keywords: Graphic design, Research, Teaching, Metaphor, Discourse.

\section{INTRODUCCIÓN}

Debemos reconocer que, en la actualidad, es sensible un cierto hartazgo de estímulos visuales sin respuesta supuestamente conformados para la comunicación visual. También es evidente que, en este contexto comunicativo, los comportamientos sociales son modificados considerablemente debido al desarrollo de los nuevos medios técnicos de comunicación y de nuevos requisitos de carácter, habitualmente, económicos. En este sentido, resulta evidente que la evolución técnica aporta a la imagen una progresiva importancia que, por otra parte, deberíamos considerar en su aspecto puramente cuantitativo, ya que mientras por un lado es una inestimable ayuda al profesional del diseño gráfico, por otro lado ha supuesto el aumentar peligrosamente la saturación de información gráfica. Ante esto, también resulta incuestionable la reafirmación ineludible de que las necesidades del ser humano no están, o no deben estar, delimitadas únicamente por aquellas de carácter técnico o económico. Necesidades de tipo psicológico, cultural o estético, es decir, aquellas que determinan en gran medida el concepto general del diseño gráfico, requieren de nuevas áreas de apoyo que permitan la comprensión de la dinámica social, dando con ello un verdadero sentido a las producciones del diseño gráfico. Al mismo tiempo debemos reconocer que las propias necesidades y condicionantes de tipo económico y de premura, innatas a la profesión del diseño gráfico, no permiten la necesaria inversión en investigación que provoque propuestas acordes con los verdaderos requisitos de nuestra cultura, entendiéndola como patrón de significados incorporados a las formas simbólicas. Unas formas simbólicas en virtud de las cuales las personas nos comunicamos y compartimos experiencias, concepciones y creencias particulares. Es por ello que en las propuestas de enseñanza en el campo del diseño gráfico es incuestionable la inclusión de nuevos mecanismos de investigación que incentiven y proporcionen nuevos procesos de creación basados en la experimentación gráfica, que más allá de representar un reflejo de un modelo cultural general dé primacía a la autorreflexión.

Es evidente que desde nuestra responsabilidad docente e investigadora no puede plantearse el diseño gráfico como un acto de mero control tecnológico o de servilismo al cliente. Nuestra disciplina, hoy más que nunca, debe plantearse como un medio de construcción cultural que permita generar experiencias visuales enriquecedoras para nuestro entorno cotidiano a partir de la creación de nuevas relaciones visuales que ayuden a sentir y a pensar. Estas nuevas relaciones visuales, determinadas por el 
significado de las formas, la imaginación creativa, las facultades de composición y combinación, la abstracción formal, la comprensión simbólica, la capacidad de análisis, etc., deben ser el objeto de un entrenamiento fundamentado en la investigación. En consecuencia, el objetivo de la enseñanza en diseño gráfico no debe ser tanto el producto en sí mismo sino el proceso mental, con recursos pedagógicos dirigidos hacia los aspectos de sensibilidad, hacia un pensar conceptual y el experimento, buscando recursos de expresión nuevos. En cualquier caso el objeto creado ha de ser reflejo de una actitud creativa e innovadora que busque soluciones significativas y renovadoras para una comunicación visual eficaz.

Desde una definición del diseño gráfico como un mecanismo de alteración del orden preestablecido, indagando en las formas desde su relación con los sujetos y sus entornos físicos y culturales, podemos establecer que esta disciplina posee un campo que le es exclusivo: la investigación en el mundo perceptivo del ser humano para obtener formas expresivas auténticamente comunicativas. Analizar condicionantes, buscar y revisar recursos simbólicos, combinarlos, adaptarlos, descubrir nuevos espacios de significación..., de eso trata el diseño gráfico. En este sentido, no es posible hablar de diseño gráfico sin hablar de instrucción gráfica. Como disciplina artístico proyectual es vital considerar en los procesos de formación un concepto de investigación básica que proporcione al alumnado la capacidad de buscar valores y conocimientos para así poder aprender a encontrar, comprender, manipular, desarrollar y aplicar imágenes. Y con ello extender y hacer más eficaces las potencialidades del alumnado, permitiéndole modificar su entorno natural.

De acuerdo con estas premisas, la propuesta pedagógica que presentamos debe estimarse como un esfuerzo más de orientación hacia el desarrollo de la aptitud ingenio-inventiva a través de la investigación gráfica. Un planteamiento que pretende descubrir y potenciar la actitud creativa en el alumnado como orientación básica permanente y trascendente, creando el clima intelectual necesario para favorecer y estimular los procesos sobre los cuales se fundamentan las iniciativas del acto creador. Una metodología de un primer nivel del proceso de educación en diseño gráfico en el que se trata de aprender y aprehender nuevas formas del lenguaje para «decir visualmente». En definitiva, investigar y experimentar con las formas, descubrir las normas que las organizan, sintetizarlas, comprenderlas, manipularlas, contravenirlas, etc. Todo ello para seguir insistiendo en el hecho incuestionable de que diseñar es siempre «ir más allá» de lo esperado para que surjan nuevos sentidos.

\section{LA METÁFORA, «INGENIO Y FIGURA»}

Para nuestro caso de estudio partimos de la idea de que nuestra percepción del mundo se basa en nuestra capacidad para comprenderlo, integrándolo a nuestra psiquis e interiorizándolo a través de 
figuraciones singulares. Unas figuraciones internas que podrán ser posteriormente exteriorizadas a través de figuras de sentido particulares. Estas figuras de sentido tienen relación con los procesos de significación por analogía con los rasgos de un objeto. De ello se infiere que la comparación constituye el mecanismo que pone en contacto dos mundos para conseguir un efecto deseado: dar a entender, definir, sorprender, divertir, cautivar, etc. Esta es la base de lo que comúnmente se denomina lenguaje figurado, algo que ya desde la antigua Grecia fue concebido con el nombre de poiesis (poesía). La poesía supone un intenso proceso de introspección e interacción con el entorno exterior del sujeto y siempre implica que se «dice» más de lo que se «enuncia». Desde esta perspectiva, tal y como plantea Pfeiffer (1996), la interrelación del ser humano con su entorno es una acción poética en la cual no existe un signo perfecto para poder expresarlo. Y sin embargo es preciso una figura para poder «decir», para poder «ser»y para poder «aparecer». Así es como los seres humanos debemos buscar recursos de asociación en los signos y símbolos que habitualmente poseemos y manejamos para dar cuerpo formal, o figura, a nuestra visión de lo real. Para ello se debe realizar el esfuerzo consciente de generar nuevas ideas o conceptos, o de establecer nuevas asociaciones entre ideas y conceptos conocidos a través del ingenio, para ampliar las posibilidades semánticas o de significación que estas figuras pueden llegar a extender a partir de las asociaciones que con ellas realizamos los seres humanos. Esta es la manera en la que el sentido figurado entra en el ámbito del discurso literal, generándose el discurso figurativo, dentro del cual el recurso esencial será la metáfora, figura discursiva por excelencia. Una figura que se constituye en sí misma como el puente de tránsito necesario en la comprensión de un dominio de la experiencia, que puede ser complejo y abstracto, a partir de un dominio de origen, más básico y cotidiano (Jiménez, 2012, p.215).

Es posible que, para la mayoría de la gente, la metáfora suponga un recurso de la imaginación poética y de los ademanes meramente estéticos de la retórica, una cuestión de lenguaje extraordinario más que ordinario. Sin embargo la metáfora impregna la vida cotidiana, no solamente en el lenguaje sino en el pensamiento y en la acción, ya que puede llegar a cumplir una función cognitiva esencial entendida como uno de los mecanismos privilegiados de percepción de la realidad. En este sentido, tal y como establecen Lakoff y Johnson (1980), el sistema conceptual del ser humano mediante el cual pensamos y actuamos es fundamentalmente de naturaleza metafórica. En nuestra vida cotidiana todos recurrimos en determinados momentos al uso de figuras metafóricas. Las utilizamos para describir lo que hasta el momento no existe, para intentar aclarar conceptos que no alcanzamos a definir exactamente, para transmitir pensamientos y siempre con una intención primordialmente didáctica, descriptiva o explicativa: «Europa nos ha cerrado el grifo», «el dinero es la llave de muchas puertas», «debemos ponernos las pilas», «el cuerpo es una máquina», «está en la flor de la vida», etc. En 
definitiva, las figuras metafóricas representan el ingenio creativo del ser humano dentro de sus recursos lingüísticos para la comunicación.

En una definición específica, la palabra metáfora proviene de los términos griegos meta y pheren, que pueden ser traducidos como «más allá» y «trasladar» y supone una figura retórica que sugiere una comparación de algo con un objeto o concepto distinto con el que puede establecerse una semejanza. Desde esta definición, la metáfora es un mecanismo de la cognición humana que compromete a todos los tipos de lenguaje humano, tanto verbal como visual y tiene su base en la experiencia física y cultural de los seres humanos, apelando al pensamiento de sus receptores. Es decir, la metáfora permite manejar conceptos abstractos y complejos mediante otros más concretos y sencillos. Dicho de otra manera, la metáfora como recurso cognitivo para la comunicación permite la interacción de significados al combinarse formas, volviendo al mensaje más rico.

Función estética, cognitiva o persuasiva, la metáfora ya fue definida por Aristóteles como el hecho de «transferir a un objeto el nombre que es propio de otro». También podemos encontrar en Aristóteles otra consideración del carácter cognoscitivo de la metáfora «que nos instruye y nos hace conocer» así como el reconocimiento de que la construcción de metáforas se debe al ingenio natural de las personas para «saber apreciar las semejanzas». La creación de metáforas está basada en la capacidad humana de asociar la imagen de un elemento con la imagen de otro. Así es como los objetos que están presentes en la vida cotidiana han sido fuente constante de inspiración para las expresiones metafóricas: 
FIGURA 1: En este ejemplo podemos apreciar como un dominio de origen (una manzana) puede quedar inscrito en una lógica que lo hace significar a diferentes dominios de destino (tentación, juventud, sabiduría, pecado, discordia, inmortalidad, salud, etc.). Un recurso que se significa particularmente en las cubiertas de libros.
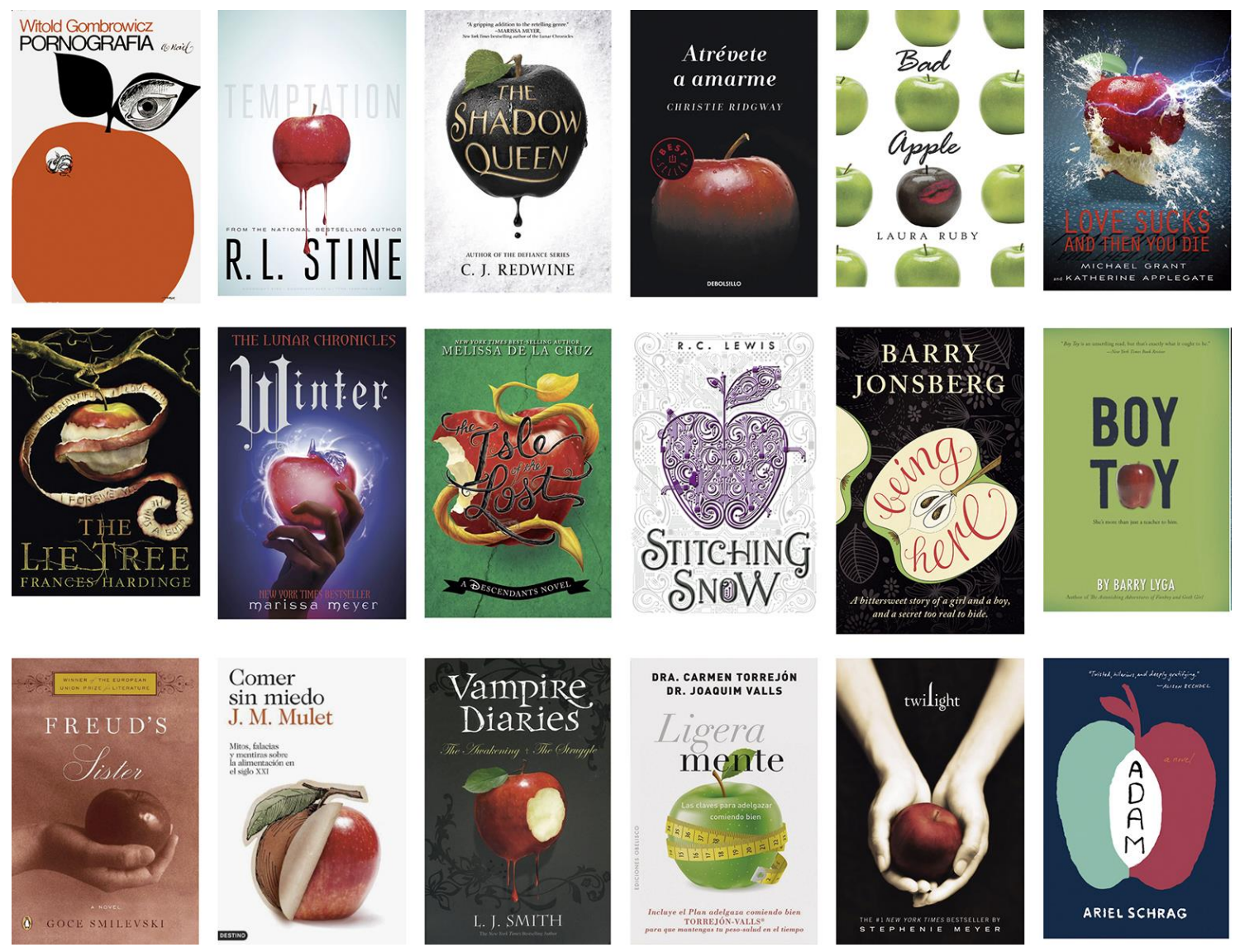

Desde la definición genérica del diseño como «ir más allá» y desde una consideración particular del diseño gráfico como construcción discursiva, la metáfora se nos presenta como un mecanismo fundamental en todo orden discursivo especializado. Y un discurso, como acción, implica una organización que siempre va más allá de las figuras a las que recurre para conformarlo.

\section{UNA MUESTRA DE INVESTIGACIÓN CREATIVA PARA VER «MÁS ALLÁ»}

Desde estas premisas, la propuesta pedagógica que estamos desarrollando actualmente en un primer nivel de enseñanza del campo específico del diseño gráfico, en el Grado de Creación y Diseño de la Facultad de Bellas Artes de la Universidad del País Vasco/Euskal Herriko Unibertsitatea, pretende desarrollarse en un ambiente que podemos considerar de «laboratorio de investigación» en el cual se comprueben hipótesis de partida y se desarrollen experimentos para llegar a un fin comunicativo. Un lugar, en consecuencia, donde favorecer un proceso experimental sobre el cual fundamentar el pensamiento creativo. 
Desde una definición de laboratorio como un lugar específico destinado a realizar investigaciones, experimentos y prácticas asociado generalmente a los trabajos de carácter científico, partimos desde la consideración de que el diseño y la ciencia se definen desde un objetivo en común, como es el deseo de avanzar en la verdad. Ahora bien, resulta necesario aclarar que las experiencias metafóricas no son las mismas que aquellas que determinan el proceso de conocimiento que surge de la investigación científica. La verdad metafórica es la que insiste en la pregunta más que en la respuesta, impulsando ir «más allá» de los conceptos aceptados. El uso de metáforas en diseño gráfico abre la posibilidad de significados plurales, estimulando la imaginación a «pensar más» a nivel de concepto. Por lo tanto, las investigaciones en metáforas visuales no pertenece a la lógica formal de la demostración sino a la lógica informal de la argumentación. Tal y como argumenta Oliveras (1993, p.257), de la demostración podemos decir que es correcta o incorrecta mientras que de los argumentos debemos decir que son más o menos fuertes, más o menos convincentes.

Centrándonos en el desarrollo de nuestro «laboratorio de argumentaciones» y desde el objetivo de estimular a «hacer algo con algo», es decir, intervenir, proyectar, construir, dotar de un nuevo sentido, etc., partimos de una recopilación de objetos comunes, o «muestras de laboratorio», que extraídos de su cotidianidad y aislados de su contexto originario deberán ser reinterpretados por el alumnado en una dimensión metafórica. Un cambio de sentido que deberá ser el resultado de un pensamiento sobre los objetos que revele la existencia de otras ideas, que a su vez permitan una interpretación capaz de construir determinados significados en una cubierta de libro. 


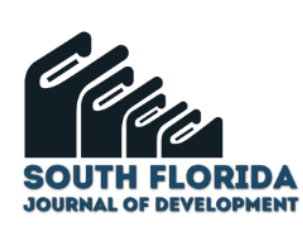

FIGURA 2: «Muestras de laboratorio». A partir de una recopilación de objetos cotidianos que nos rodean se trata de proyectar y hacer prevalecer sobre ellos una mirada poética sobre la mirada meramente utilitaria. A partir de un primer contacto con estos objetos, se debe considerar la capacidad de éstos para absorber ideas que nos emocionan y nos conmocionan, que nos conmueven y nos remueven.



Tal y como hemos definido anteriormente, el diseño gráfico es una disciplina discursiva orientada a la acción comunicativa. Y hablar de discurso es plantear una forma organizada de acción entre las personas, una práctica social que constituye situaciones, identidades sociales o relaciones entre personas. Así, desde un punto de vista discursivo, podemos definir el diseño de cubiertas de libros como la configuración de piezas textuales orientadas a unos fines y que se presentan en interdependencia con el contexto sociocultural. Desde esta consideración del diseño de una cubierta de libro como un discurso visual, en este laboratorio, a través de metáforas visuales, se intenta hacer comprender al alumnado que los discursos visuales deben encaminarse «más allá» de lo esperado para que surjan nuevos sentidos verdaderamente comunicativos.

A partir de una propuesta de títulos de diversos libros y una vez seleccionado uno de ellos por parte de cada grupo de trabajo, se deben consensuar y definir unas palabras clave, o principios lingüísticos del proceso de diseño, que sinteticen el contenido de dicho libro. A partir de ahí cada grupo deberá analizar, seleccionar y relacionar algunos objetos con diferentes aspectos del contenido discursivo del libro, transformando las cosas y su significado a través del pensamiento perspicaz, provocando el juego que relacione lo ordinario con lo imaginario y diferenciando lo insignificante con lo insólito. En definitiva, se deben buscar y descubrir con una mirada diferente las cualidades secretas que pueden estar en algunos objetos. Con la mínima alteración de los atributos formales de estos 
objetos se deben construir nuevos valores cargados de simbolismo, resaltando los valores metafóricos y discursivos de los mismos.

FIGURA 3: Proceso del trabajo del «laboratorio de metáforas».

\section{Proceso del trabajo}

Fase de REFLEXIÓN (análisis)

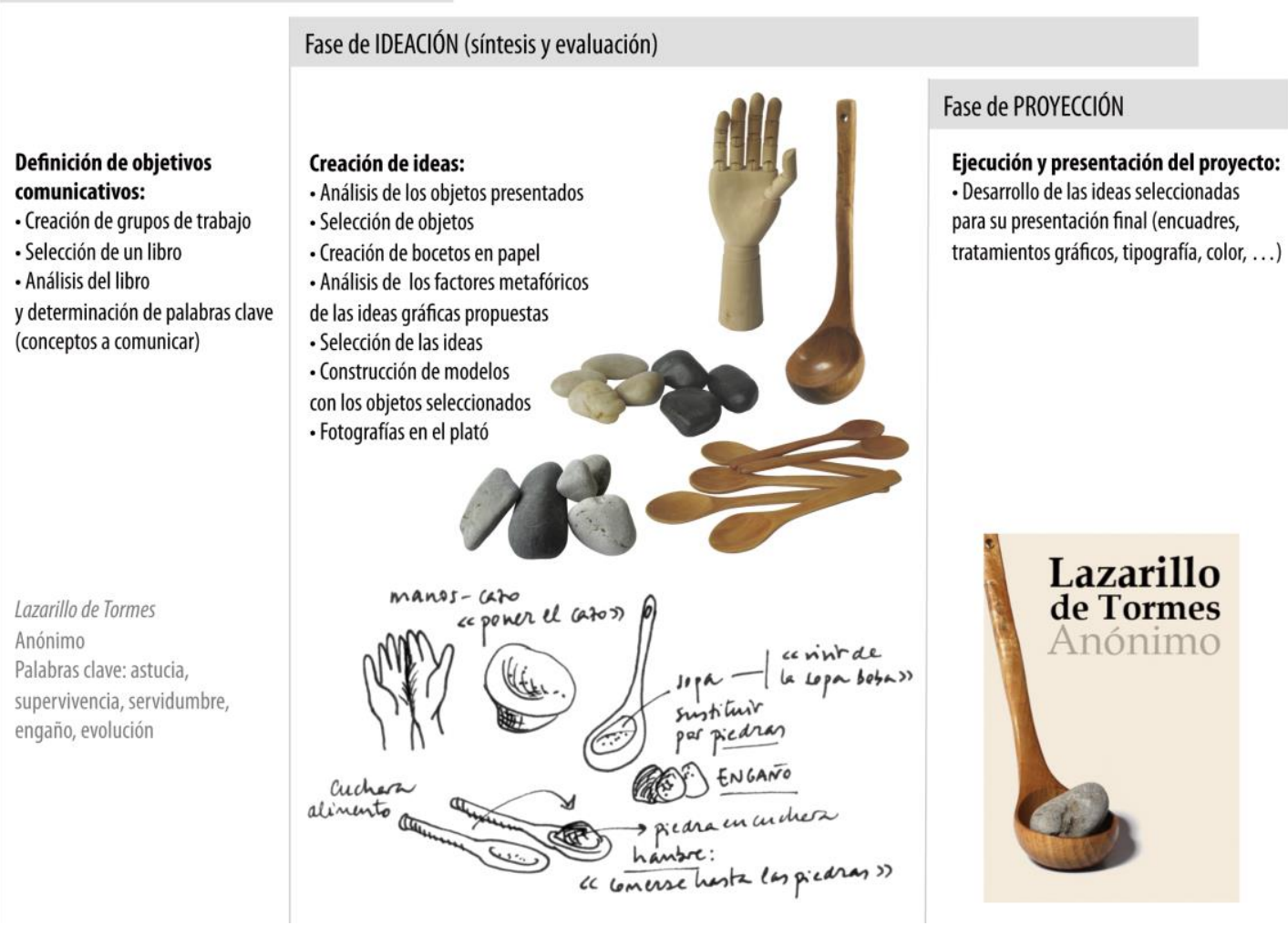




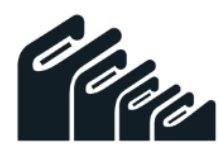

SOUTH FLORIDA

JOURNAL OF DEVELOPMENT

FIGURA 4: Ambiente del laboratorio.
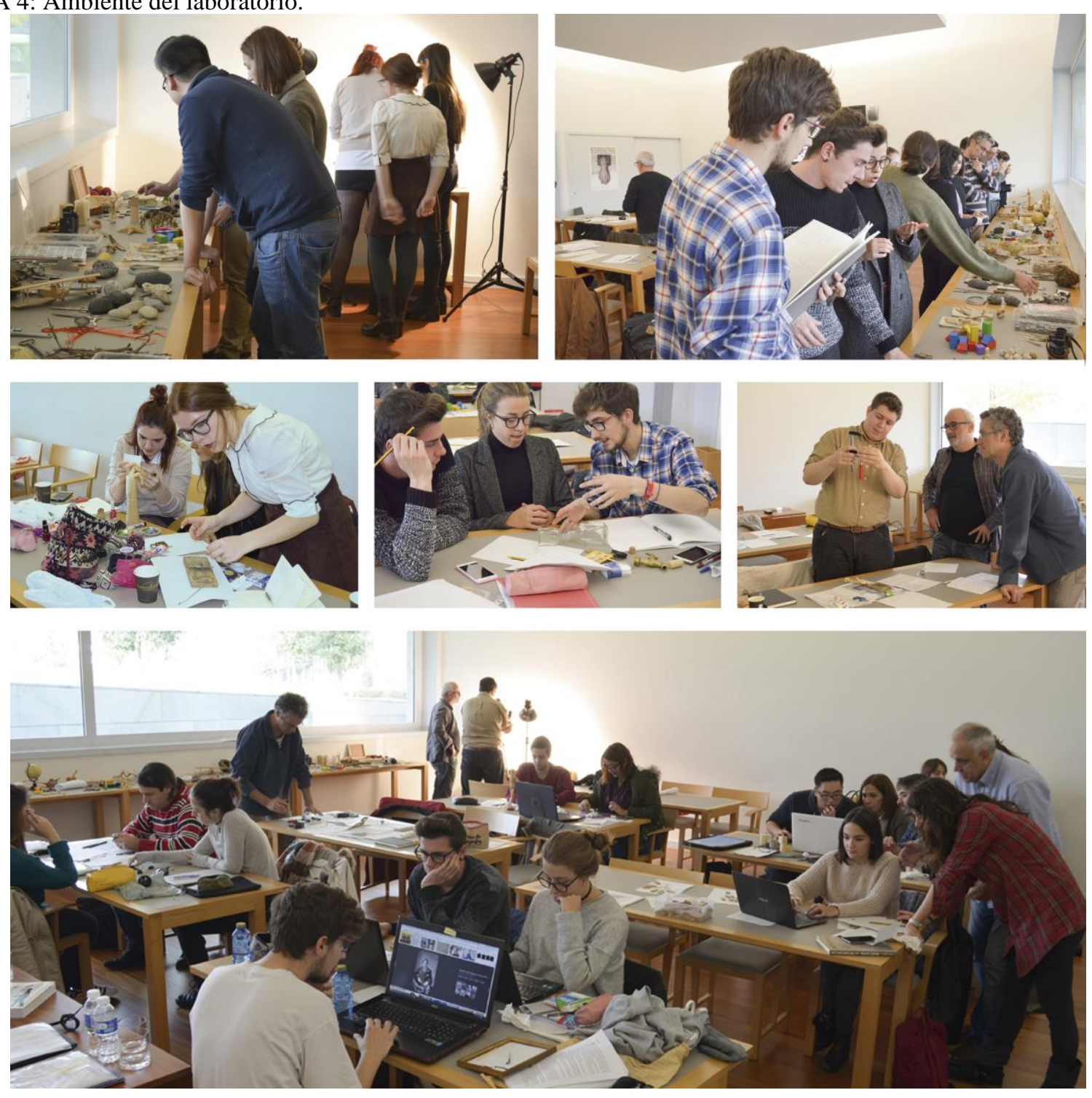

Esta experiencia de enseñanza-aprendizaje, basada en la búsqueda de relaciones metafóricas de diversos objetos con significados comunes de partida, se convierte en una prueba de ensayo para vincular lo ordinario con lo imaginario y con ello resaltar lo insólito de lo banal al servicio de la comunicación visual a través de cubiertas de libros. Una experiencia que, en definitiva, debe entenderse como una práctica investigadora que suponga en el ámbito de la enseñanza del diseño gráfico un mecanismo esencial al servicio de un orden discursivo especializado.

\section{RESULTADOS}

En los resultados finales de la experiencia de este laboratorio que presentamos queremos evidenciar el carácter esencialmente metafórico de las cubiertas realizadas. Y lo son por su poder de 
expresar o connotar el contenido del texto, tal y como podemos apreciar en el siguiente ejemplo en el que se ilustran diferentes capas de sentido de una de las cubiertas de libro realizas en el laboratorio:

FIGURA 5: En este ejemplo de boceto de cubierta de libro se produce una vuelta del significado literal para que pueda surgir un nuevo significado. La asignación ilógica (botones y disposición tipográfica del título) adquiere sentido (niño judío y niño alemán/intercambio - «pijama»/verja separadora del campo de concentración).

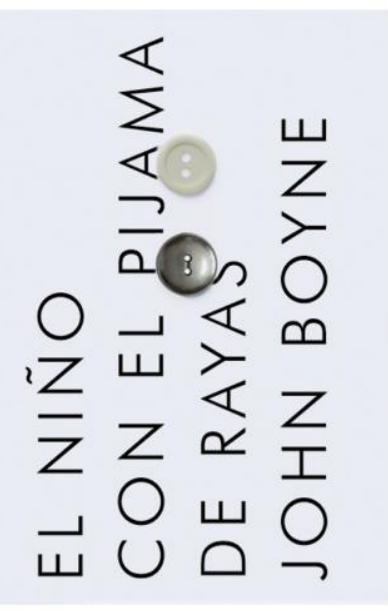

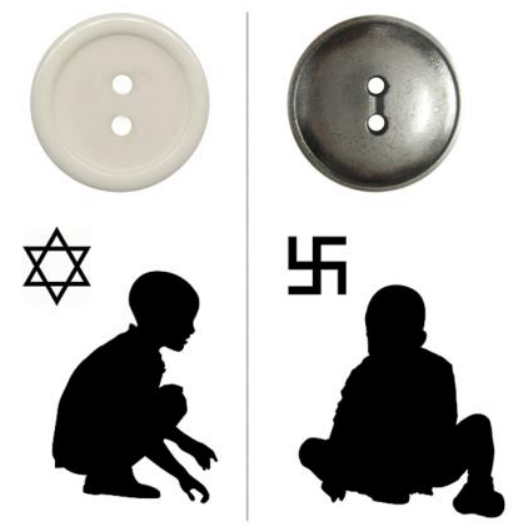
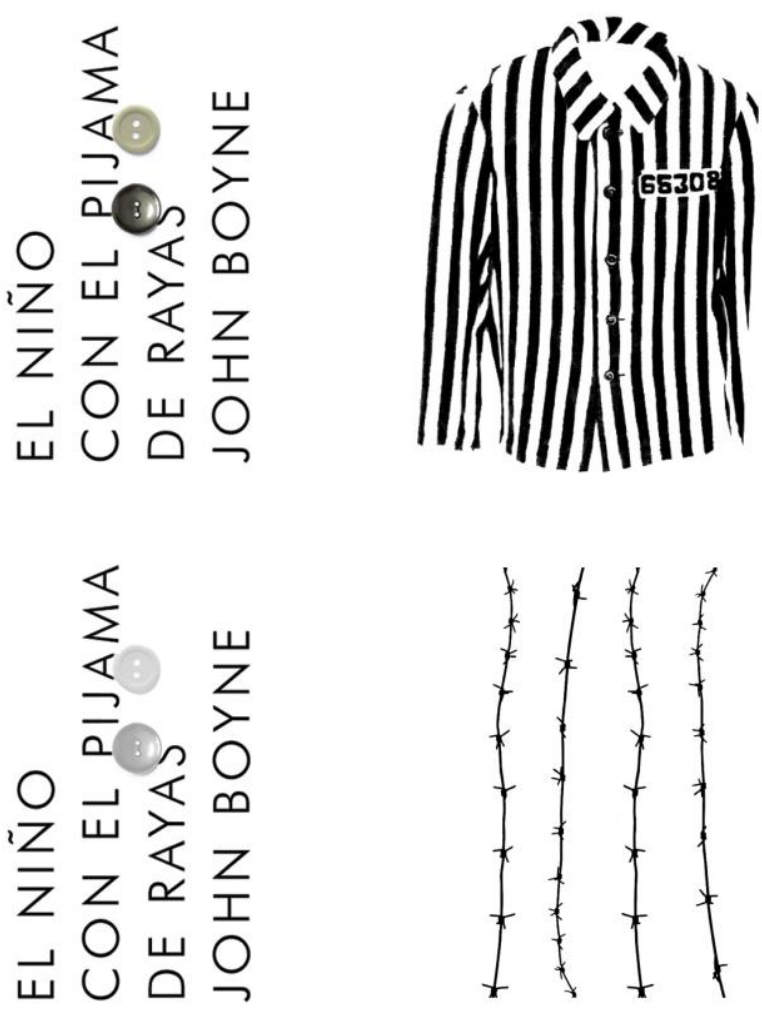

Libro: El niño con el pijama de rayas. John Boyne.

De carácter figurativo o abstracto, las diferentes propuestas de cubiertas de libros realizadas por los alumnos participantes en el laboratorio presentan imágenes en cualidades semejantes a las del texto. Y son imágenes, efectivamente, porque presentan a los ojos y a la memoria cosas ausentes, cosas que están en otro lugar y/o en otro tiempo (Costa, 2008, p.100). Aludiendo a ese texto a través del «desvío 
de la imagen» se accede en todos los casos al nivel retórico. Desde este punto de vista podemos decir que todas las cubiertas de libros son retóricas porque son esencialmente metafóricas.

FIGURA 6: Algunos resultados de las cubiertas de libros.
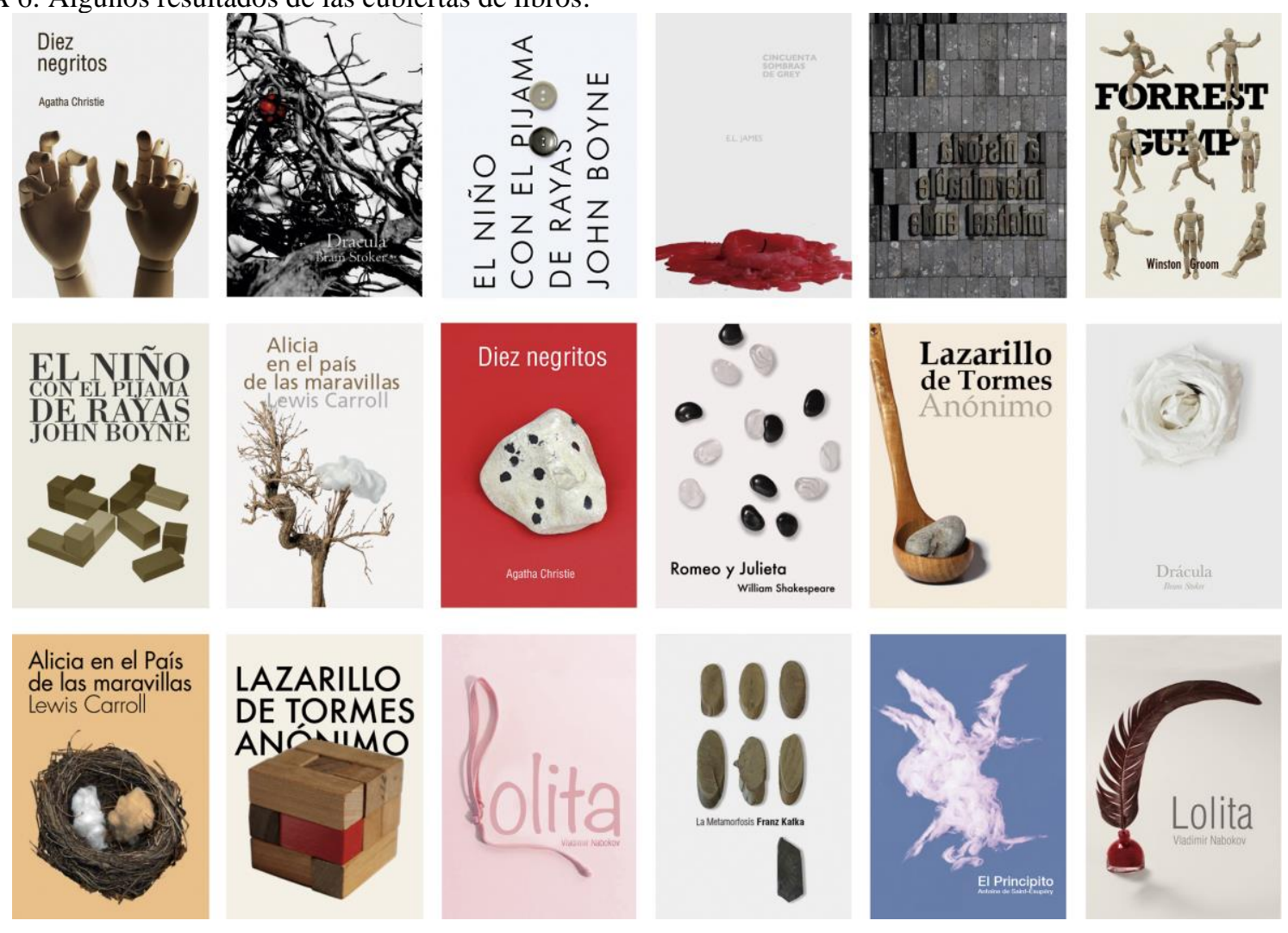

\section{CONCLUSIONES}

La importancia de abordar investigaciones en torno a la dimensión metafórica del medio visual, dentro de los procesos de enseñanza del diseño gráfico, estriba en su condición de creación de modelos. No podemos olvidar que es gracias a modelos perceptivos visuales como podemos alcanzar a entender lo que frecuentemente se describe a nivel de imaginación. En este sentido planteamos que al igual que las metáforas verbales sirven de modelos del trabajo poético, la investigación sobre las metáforas visuales han de servir para reflexionar y crear modelos perceptivos, algo que penetra esencialmente en los discursos del diseño gráfico.

La metáfora abre las posibilidades de resemantización de las figuras, orientando el discurso hacia un novedoso ámbito de interpretación e incrementando el sentido de lo que se pretende comunicar, posibilitando a la vez un mayor nivel de persuasión. De donde resulta que las metáforas visuales pueden funcionar como mecanismos de investigación para ver «más allá». Algo que implica necesariamente creatividad. Desde esta consideración de la metáfora, como posibilitadora del entendimiento y la especulación sobre «cosas en términos de otras cosas», planteamos la investigación 
en la creación y percepción metafórica en el proceso de enseñanza y aprendizaje del diseño gráfico como recurso vital para la creación de conocimiento sobre el ser humano y su entorno comunicativo visual.

La experiencia de enseñanza en el campo del diseño gráfico que presentamos, consistente en la creación de cubiertas de libros configuradas desde una consideración metafórica de objetos comunes y realizada en un ambiente de trabajo de «laboratorio de imagen», supone un proceso experimental que pretende generar en el alumnado, desde un principio, una actitud de desafío ante conceptos y restricciones tradicionales. Y con ello inculcar de manera permanente y trascendente nuevos criterios de diseño. Desde una consideración del diseño gráfico como lenguaje, con esta propuesta práctica de enseñanza también se intenta adentrar al alumnado en la comprensión del diseño gráfico como agente del discurso visual. Un discurso visual en el que la metáfora supone un elemento esencial para su elaboración en cualquier contexto donde lo textual tenga existencia.

Entendemos que la investigación sobre la potencial dimensión metafórica de objetos sustraídos del entorno cotidiano permite facilitar la comprensión del resalte de significados comunes. Y así facilitar la adquisición de nuevas perspectivas y referencias sobre la realidad ya existente de la comunicación visual. Unos aspectos que no pueden ser percibidos pero que pueden ser «imaginados a través de la imagen» para descubrir, por ejemplo, cubiertas de libros. En definitiva, a través de un proceso experimental de creación gráfica se intenta que el alumnado descubra nuevos sentidos verdaderamente comunicativos mediante el uso de la dimensión metafórica que puede originarse con una manera diferente de ver los objetos cotidianos que nos circundan. Y todo esto para seguir anhelando el ir «más allá» en el diseño gráfico y en nuestra propia labor docente. 


\section{REFERENCIAS}

Calsamiglia, H., y - Tusóns, A. (2001). Las cosas del decir. Manual de análisis del discurso. Barcelona, España: Ariel.

Costa, J. (2008). La forma de las ideas. Cómo piensa la mente. Estrategias de la imaginación creativa. Barcelona, España: Costa Punto Com Editor.

Fernández, L. (2007). El discurso del diseño gráfico. Bilbao, España: Diseiñu: Ikus Komunikazioa.

Fernández, L., y Herrera, E. (2016). Diseño de cubiertas de libros. Recursos de retórica visual. Madrid, España: Editorial Síntesis.

Jiménez, R. (2012). La palabra, la metáfora y la resemantización del discurso científico. Revista Ciencias de la Educación, 22 (40), 212-223.

Oliveras, E. (1993). La metáfora en el arte. Buenos Aires, Argentina: Editorial Almagesto.

Lakoff, G., y Johnson, M. (2005). Metáforas de la vida cotidiana. Madrid, España: Cátedra.

Pfeiffer, J. (1966). La poesía. México: Fondo de Cultura Económica de España. 